\title{
0 professor-pesquisador-reflexivo: debate acerca da formação de sua prática
}

\section{The teacher as a reflective researcher: debate on his/her educational practice development}

\author{
Maria Lília Imbiriba Sousa Colares* \\ Tadeu Oliver Gonçalves** \\ Anselmo Alencar Colares ***

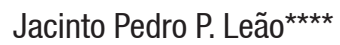

\begin{abstract}
Resumo: O presente artigo tem como finalidade analisar a necessidade da formação da prática do professor-pesquisador-reflexivo. Objetiva refletir o processo da formação da prática do professor, tanto a pautada na racionalidade técnica quanto a norteada na epistemologia da prática. Compreendemos que a formação da prática do professor-pesquisador-reflexivo tem como fundamento o diálogo ininterrupto com as outras ciências. A reflexão, a pesquisa e o ensino estão sendo problematizados e (re)construídos pela práxis docente investigativa, à medida que (re)pensam e (re)constróem a complexidade da vida, isto é, do texto-contexto. Educar, nesta concepção, é, sobretudo, por um lado, desconstruir a racionalidade técnica e, por outro lado, construir a epistemologia da práxis investigativa do professorado. Além disso, é estar indignando-se e intervindo no mundo para transformá-lo e torná-lo mais justo e humano.
\end{abstract}

Palavras-chave: Professor pesquisador. Prática reflexiva. Formação.

Abstract: This article aims to analyze the necessity of practical training for teacher-as-reflectiveresearchers. In particular, it reflects on the process of teaching practice, both in terms of technical rationality and the epistemology of practice. It assumes that teaching practice is based on a continuous dialogue with other sciences. Reflection, research and teaching are constantly being problematized and (re)constructed through investigative teaching praxis, as they help to (re)think and (re)construct the complexity of life, that is, of text-context. From this standpoint, on the one hand educating is above all about deconstructing technical rationality and on the other hand it is about constructing the epistemology of investigative praxis of the teacher. Furthermore, it is also about being indignant and intervening in the world to transform it and make it more equal and humane.

Keywords: Researcher teacher. Reflective practice. Development.

\footnotetext{
* Doutora em Educação. Professora da Universidade Federal do Oeste do Pará (UFOPA). Docente do Programa de Mestrado em Educação da Universidade Federal de Rondônia (UNIR). E-mail: <liliacolares@ufpa.br>.

** Doutor em Educação. Professor da Universidade Federal do Pará (UFPA). E-mail: <tadeuoliver@yahoo.com.br>.

*** Doutor em Educação. Professor da Universidade Federal do Oeste do Pará/UFOPA. Docente do Programa de Mestrado em Educação da Universidade Federal de Rondônia (UNIR). E-mail:< anselmo.colares@hotmail.com>. **** Mestre em Educação em Ciências e Matemática. Professor da Universidade Federal de Rondônia (UNIR). E-mail: <jacintoleao@yahoo.com.br>.
} 


\section{Incursões introdutórias}

Há o reconhecimento entre os educadores crítico-dialéticos, fundamentados na ética universal humana (FREIRE, 1997), da inadiável formação de professores que consigam corporificar atitudes críticas e reflexivas sobre as implicações da racionalidade técnica e da epistemologia da prática à vida dos professores e ao cotidiano escolar. Para tanto, “(re)pensar a [...] prática reflexiva é imprescindível [para] encará-la como a vida à superfície das teorias práticas do professor, para análise crítica e discussão" (ZEICHNER, 1993, p. 21).

É importante esclarecermos, de início, que

[...] o movimento do prático reflexivo e do professor pesquisador surge em oposição às concepções dominantes de 'racionalidade técnica', em que as práticas profissionais se produzem num contexto de divisão social do trabalho entre concepção e execução, ou seja, entre teoria e prática. (LÜDKE et al, 2001a, p. 28)

A práxis do educador investigador-reflexivo é multidimensional, pois tem como substrato a afetividade, a emoção, a cognição, o lúdico, a memória e o imaginário. Essas são algumas das dimensões presentes na vida dos professores. Todavia, várias das instituições de formação para o magistério, como salienta Imbernón (1994, p. 20), demonstram pouca preocupação com a formação psicopedagógica dos docentes, provocando, assim,

[...] grandes disfunções tanto na formação inicial como na permanente, [pois] unicamente a partir de uma definição clara das necessidades formativas dos futuros professores poderia se estabelecer um curriculum coerente e um plano de estudos que contemplasse harmonicamente os programas, as metodologias, a evolução, as práticas etc., com o fim de dotar os novos educadores de uma formação científica, psicopedagógica e cultural competente.

Imbernón (1994, p. 46) afirma que é indispensável formar a prática dos professores, pois

Cuidar [da práxis] dos professores novos será fundamental para o sistema educativo [para a sociedade], sobretudo em um coletivo donde as categorias profissionais realizam tarefas iguais e muito similares.

A participação crítico-dialética do professor na vida escolar e fora dela contribuirá sem sombra de dúvida para a sua permanente formação: científica, tecnológica, política e psicopedagógica. Ela pode contribuir na discussão, na elaboração, na organização e na efetivação do planejamento pedagógico da escola. Com relação às necessidades da comunidade extra-escoltar, poderá problematizar, junto com eles, as condições materiais e simbólicas favoráveis à construção da qualidade de vida. Portanto,

[...] a formação permanente do período de iniciação, ao longo do qual o professor recebe informação de seus companheiros, facilita a assistência a cursos e conferências sobre temas pedagógicos básicos. É de se supor o professor receber uma fundamentação psicopedagógica para afrontar os problemas que surjam para poder construir posteriormente os novos conceitos didáticos na hora de elaborar o currículo adequado aos alunos [considerando o contexto social, cultural, político e econômico, onde estão inseridos]. (IMBERNÓN, 1994, p. 50)

A prática formativa docente do investigador-problematizador é prenhe de conhecimentos científicos, do mundo, da vida. Por isso, consideramos [...] inquestionável 
a importância do papel da formação teórica para o pesquisador. É a teoria que vai muni-lo de elementos para interrogar os dados e procurar entender a trama de fatores que envolvem [a formação de sua prática de professor-pesquisador-reflexivo de matemática] (LÜDKE, 2001b, p. 42).

A pesquisa ${ }^{1}$ da prática docente, ou seja, da sua formação (enquanto espaço problematizador-reflexivo) é hoje reconhecida na comunidade educacional. Lüdke (2001a, p. 49), no entanto, espanta-se quando não encontra em algumas instituições de ensino

[...] um tipo de pesquisa bastante popular na comunidade educacional atual, aquela voltada para a análise da própria prática do professor, que merece atenção pelo seu potencial de desenvolvimento crítico, bastante acessível ao professor.

A prática é um espaço corpóreo e multilateral (inclui o todo), onde convivem a sensibilidade, a ciência e a empiria. O diálogo entre elas é o fulcro da dimensão humana e ética da prática educativa docente. Adicionando-se o diálogo na práxis, multiplica-se a possibilidade de interagir, conhecendo, sabendo, apalpando e cheirando o cosmo.

Schön (1992, 2002), Zeichner (1993), Freire (1997) e Bortoni-Ricardo (2008) concebem a pesquisa da prática docente e da vida escolar como um instrumento metodológico para repensá-las e para aumentar a qualidade do trabalho educativo-crítico-emancipatório. Esses autores, cada um com pontos específicos de trabalho, consideram primordial a

[...] articulação entre teoria e prática na formação docente, [reconhecendo] a

\footnotetext{
1 “A questão da importância da pesquisa na prática docente vem há muito tempo sendo discutida em associações, com os conceitos de reflexão e crítica, sob a perspectiva de uma prática reflexiva, do professor reflexivo ou pesquisador” (LÜDKE et al., 2001a, p. 36).
}

importância dos saberes da experiência e da reflexão crítica na melhoria da prática, [atribuindo] ao professor um papel ativo no próprio processo de desenvolvimento profissional, e [defendendo] a criação de espaços coletivos na escola para desenvolver comunidades reflexivas. (ANDRÉ, 2001, p. 57)

A formação inconclusa da prática do professor-pesquisador-reflexivo é forjada no contato e na presença do diálogo insofismável entre ciência, tecnologia, sociedade e cultura. Logo, a

[...] prática reflexiva é composta de dois níveis fundamentais: a reflexão-na-ação e reflexão sobre a prática, incluindo a reflexão sobre a reflexão-na-ação. (LÜDKE et al., 2001a, p. 23)

A prática crítico-dialética docente é renovada pela e na pesquisa sobre o cotidiano de sala de aula. É fundamental considerar

[...] a pesquisa como uma espécie de facilitadora da prática reflexiva; [...] a pesquisa como um estágio avançado de uma prática reflexiva; [...] a prática reflexiva como uma espécie de pesquisa. (LÜDKE et al., 2001b, p. 41)

É preciso invadir e ocupar as bibliotecas, as escolas, as universidades, no sentido de aguçar a prática da leitura das palavras e dos contextos. Muitos estão distantes desses lugares. Acompanhando a (re)leitura crítico-dialética, a problematização e a reflexão (cálcio e oxigênio da prática docente emancipatória), o professor-pesquisador-reflexivo, com os alunos, desvelará o mundo. Porém,

A preguiça intelectual inibe a prática reflexiva. [...] os professores que querem delegar suas preocupações profissionais para a escola e que não gostam de desesperar-se não se tornam profissionais reflexivos. (PERRENOUD, 2002, p. 52) 
Um convite irrecusável aos indignados e aos incomodados da terra é a (re) criação da prática do professor-pesquisador crítico e dialético, movimentado pelo amor às pessoas. Freire (1997, p. 58) enaltece esse amor dizendo:

Gosto de ser homem, de ser gente, porque não está dado como certo, inequívoco, irrevogável que sou ou serei decente, que testemunharei sempre gestos puros, que sou e que serei justo, que respeitarei os outros, que não mentirei escondendo o seu valor porque a inveja de sua presença no mundo me incomoda e me enraivece. Gosto de ser homem, de ser gente, porque sei que minha passagem pelo mundo não é predeterminada, preestabelecida.

Precisa-se formar a prática de professores que sejam amigos do saber e do conhecer, da (re)leitura inveterada (mas prudente e humilde) da linguagem conceitual, empírica e cósmica. Essa prática é própria do professor-educador. O [...] educador problematizador refaz, constantemente, seu ato cognoscente, na cognoscitividade dos educandos. Estes, em lugar de serem recipientes dóceis de depósitos, são agora investigadores críticos, em diálogo com o educador, investigador crítico, também. (FREIRE, 1999b, p. 69).

A prática docente é o oxigênio da relação do pensar, do fazer, do saber, do ser e do sentir, corporificada ao texto e ao contexto. Ela não é vazia, e nem sem conteúdo. Não é improvisada, e nem imediatista. É (re)planejada, dialogicamente, junto aos interesses e às necessidades da comunidade escolar. É prenhe de saberes e de conhecimentos (re)construídos sob a égide da dialética texto-mundo. Assim, [...] seu objetivo não é fazer a descrição de algo a ser memorizado. Pelo contrário, é problematizar situações. É necessário que os textos sejam em si um desafio e como tal sejam tomados pelos educandos e pelo educador para que, dialogicamente, penetrem em sua compreensão. (FREIRE, 1987, p. 25).

A vida é problemática. Educar para viver de forma inquieta, crítica, dialética, para desconfiar das certezas dos discursos, dos conteúdos e das práticas de qualquer pessoa, deve-se compreender nelas a presença da concreticidade da existência das pessoas, do mundo e da realidade.

A luta, no sentido nietzscheano, significa a presença da superação das dificuldades e dos obstáculos que negam a possibilidade da (re)construção da vida, ou seja, da existência. A luta, desse modo, corresponde ao " [....] querer ir sempre além, num vir-a-ser eterno, portanto sem pensar em preservar-se. Viver é superar-se constantemente" (NIETZSCHE, 2002, p. 19).

O pensamento único neoliberalizante tenta a todo custo sepultar as práticas contrahegemônicas existentes nas instituições do ensino público. A ética mercantil, refúgio do neoliberalismo, invade as escolas e as universidades públicas, ceifando princípios da ética, soterrando vários direitos sociais e trabalhistas. Assim,

[...] as noções econômicas e tecnocráticas de eficácia, produtividade, eficiência e êxito tomam o lugar de outras, mais políticas, como de participação democrática na tomada de decisões educacionais, ou relacionada com problemáticas sociais, como a de expansão quantitativa da matrícula escolar. Esta transformação não só tende a tornar cada vez mais econômico e menos político o discurso educacional, como também leva a traduzir valores próprios da ética pública e cívica na clave da ética do lucro de mercado e do consumo: a solidariedade e cooperação cedem lugar assim à competição e ao mérito individual. (SUÁREZ, 1995, p. 261)

A prática docente insensível aos condenados da terra, aos indigentes, aos miseráveis (não que sejamos a favor da miséria, da 
indigência) é a favor da reprodução das mazelas, provocada pelo terrorismo dos donos do capital internacional e nacional (capitalismo financeiro e especulativo). O que mais nos indigna e nos apavora é perceber pessoas (consideradas esclarecidas científica e politicamente) adotarem o ethos neoliberalizante como referencial educativo e como modelo de vida. Apple (2001, p. 11) salienta que nesse momento histórico "[...] um número excessivo de nos que se acostumou ao sofrimento, nacional e internacionalmente". E alerta: “[...] Este é um período difícil para qualquer um que esteja comprometido com uma transformação social e educacional progressista."

A formação da prática sensível é prenhe de amor às pessoas. A todo instante luta pela vida. A ausência de amor e de prazer, na prática docente, permitirá concentração da riqueza (pelos donos do mundo), visto que, naquela, não se fará presente a reflexão e a problematização dialética sobre quem se beneficia das invenções e das descobertas científicas e tecnológicas, tornando estas propriedades patenteadas daqueles, comercializáveis por eles.

A educação, que norteia a formação da prática do professor-pesquisador-reflexivo conforme Apple (2001, p. 15), é

[...] um empreendimento ético. $\mathrm{O}$ aspecto pessoal é visto como um caminho para redespertar sensibilidades éticas e estéticas que cada vez mais vinham sendo expulsas do discurso científico de uma quantidade excessivamente de educadores. Ou, então, é visto como um caminho para dar vez às subjetividades de pessoas que tinham sido silenciadas.

\section{A formação da prática do professor- pesquisador-reflexivo}

A formação da prática do professoreducador, ou seja, do professor-pesquisador- reflexivo mais do nunca se faz necessária. A sua formação não é construída apenas em cursos de licenciatura, mas no permanente desenvolvimento profissional e na problematização da práxis do ensino e da aprendizagem, conectada com o mundo, isto é, com a eticidade da educação. Esta é o substrato da

[...] prática educativa, enquanto prática formativa. Educadores e educandos não podem, na verdade, escapar à rigorosidade ética. Mas é preciso deixar claro que a ética de que falo não é a ética menor, restrita, do mercado, que se curva obediente aos interesses do lucro. (FREIRE, 1997, p. 16)

O local de trabalho (a escola pública) educativo-crítico do professor está sendo atacado pela lógica mercantil. Suas investidas visam converter tudo em mercadoria altamente lucrativa. Exige-se uma formação profissional polivalente, politécnica e flexível do trabalhador, inclusive do professor. Transforma qualidade, descentralização, municipalização (defendidas pelos educadores progressistas) em categorias (na sua essência mercantilizadas) à disposição de todos, bastando ter competência e habilidade (baseadas no neodarwinismo social) pragmática, utilitária e instrumental.

Há vários processos de luta cultural entre os educadores progressistas e os tecnocratas neoliberais, envolvendo diferentes concepções atribuídas às categorias trabalho, educação, qualidade ${ }^{2}$ e formação. Para os primeiros, o trabalho

\footnotetext{
${ }^{2}$ Quando se fala em qualidade social na educação se entende que "[...] a qualificação humana diz respeito ao desenvolvimento de condições físicas, mentais, afetivas, estéticas e lúdicas do ser humano (condições omnilaterais) capazes de ampliar a capacidade de trabalho na produção dos valores de uso em geral como condição de satisfação das múltiplas necessidades do ser humano no seu devenir histórico.” (FRIGOTTO, 1996, p. 32).
} 
[...] não reduz a fator, mas é, por excelência, a forma mediante a qual o homem produz suas condições de existência, a história, o mundo propriamente humano. Trata-se de uma categoria ontológica e econômica fundamental. A educação também não é reduzida a fator, mas é concebida como uma prática social, uma atividade humana e histórica que se define no conjunto das relações sociais, no embate dos grupos ou classes sociais, sendo ela mesma forma específica de relação social. O sujeito dos processos educativos aqui é o homem e suas múltiplas e históricas necessidades (materiais, biológicas, psíquicas, afetivas, estéticas, lúdicas). (FRIGOTTO, 1996, p. 31)

O que já está acontecendo é a simbiose dos significados sociais daquelas categorias em sentidos estritamente mercantis. Há intelectuais que abandonaram valores éticos e humanos e outros que estão prestes a fazer parte da ortodoxia mercantil. O credo mercantil os convenceu de que não tem saída para a crise da educação pública, ao não ser que introduzam no seu cotidiano os valores do mercado (GENTILI, 1995)

Por outro lado, os intelectuais críticos concebem a formação da prática do professor-pesquisador-reflexivo como em permanente (re)construção científica, tecnológica e social, baseada na [...] ética propriamente humana, ou seja, a antropoética deve ser considerada como a ética da cadeia de três termos, indivíduo/sociedade/espécie, que emerge da nossa consciência e do nosso espírito propriamente humano. Essa é a base para ensinar a ética do futuro. (MORIN, 2000, p. 106)

A práxis dos educadores crítico-dialéticos, fundamentada na ética humana, ainda, se materializa na
[...] luta justa para que a qualidade humana não seja subordinada às leis do mercado e à sua adaptabilidade e funcionalidade, seja sob a forma de adestramento e treinamento da imagem do monodomestificável dos esquemas tayloristas, seja na forma da polivalência e formação abstrata, formação geral ou policognição reclamadas pelos modernos homens de negócio e os organismos que os representam. (FRIGOTTO, 1996, p. 31)

Forma-se, assim, a prática crítico-dialética do professor, principalmente, quando se pretende desconstruir as práticas e os discursos da lógica neoliberal. Nóvoa (2002, p. 38), afirma:

Hoje em dia, apresenta-se aos professores como grupo profissional um desafio decisivo: fazer face [às investidas neoliberais], criando a possibilidade, pouco a pouco, ir construindo um saber [contra-hegemônico] emergente da prática que não negue os contributos teóricos das diversas ciências sociais e humanas, mas que os integre com base em uma reflexão sobre a experiência pedagógica concreta.

Os saberes escolares e os saberes empíricos cotidianos se completam na medida em que refletem a vida dos sujeitos da educação crítico-dialética. A prática, um território em movimento dialético de (des)construção, se (re)faz pelos saberes (re)construídos e problematizados diariamente pelos professores e pelos educandos, no contexto do texto e no texto do contexto da construção das vivências das pessoas. É inconteste que os cursos de formação de professores-pesquisadores-reflexivos não prescindam da investigação dialógica, radical, rigorosa e inquieta do

[...] saber dos professores - como qualquer outro tipo de saber de intervenção social - não existe antes de ser dito. [...] Os professores possuem um conhecimento 
vivido [prático], que cada um é capaz de transferir de uma situação para outra, mas que é dificilmente transmissível a outrem. Ora, na medida em que no campo educativo o saber não preexiste palavra [dita ou escrita], os conhecimentos de que os professores são portadores tendem a ser desvalorizados do ponto de vista social e científico. (NÓVOA, 1992, p. 36)

A qualidade da prática profissional do professor-pesquisador-reflexivo implicará na qualidade do trabalho educativo, crítico e emancipatório, que é desenvolvido dentro e fora da escola. A importância de se estar investigando a formação da prática docente, entre outras finalidades, almeja preparar o [...] professor no exercício de sua prática como ator que reflete sobre as ações que realiza em seu cotidiano. O significado da preparação de docentes para o exercício de uma prática reflexiva se tornou um tema recorrente nas discussões sobre a formação do professor nas últimas duas décadas. (PAIVA, 2003, p. 47-48).

Paiva (2003, p. 48), após analisar as contribuições dos estudos feitos por Tardif, Lessard e Gautier, sobre as reformas dos cursos de formação de professores do Brasil, Canadá, Estados Unidos, França, Inglaterra, conclui que o processo da construção da identidade dos professores assume as seguintes características: a do “[...] tecnólogo do ensino, do ator social e do prático reflexivo.”

A prática do saber e do fazer do tecnólogo do ensino centra-se em

[...] conhecimentos formalizados, saídas da pesquisa científica, instaurando um ensino estratégico que tem por base o conhecimento referenciado na cognição dos alunos. (PAIVA, 2003, p. 48)

O conhecimento, pelos professores, dos instrumentos tecnológicos como meios didático-pedagógicos é fundamental para o desenvolvimento qualitativo-quantitativo do processo de ensino e de aprendizagem. No entanto, se os conteúdos trabalhados, mediante a utilização desses instrumentos, não estiverem sendo problematizados, desvelados e desmistificados a prática docente tornar-se-á tecnicista, instrumental e acrítica.

Os tecnocratas da educação, quando se referem à formação do novo trabalhador, supervalorizam a prática em detrimento da teoria, no sentido de anular e de decapitar o pensar crítico-emancipatório. Alves (1996, p. 16) argumenta:

[...] A questão não é aumentar a prática em detrimento da teoria ou vice-versa o problema consiste em adotarmos uma nova forma de produzir conhecimento no interior dos cursos de formação do educador.

A conexão teoria-reflexão-prática necessária não se concretiza sem a problematização dos sujeitos da educação acerca da relação inevitável eu-outro-mundo. Desse modo,

[...] A reflexão crítica sobre a prática se torna uma exigência da relação Teoria/ Prática sem a qual a teoria pode ir virando blábláblá e a prática, ativismo. (FREIRE, 1997, p. 24)

O professor é, junto com o discente, o ator social, político e cultural, quando a sua prática e a sua teoria (numa relação indissociável) são ética e moralmente sensíveis aos excluídos da terra. Estes, cotidianamente, são acometidos pelas mazelas da fome, da miséria, da violência etc., provenientes da ação insana e mórbida do lucro por aqueles que se consideram donos do mundo. Por causa disso, também, provocam guerras, bloqueios econômicos e crises financeiras. 
A prática do professor-educador, centrada na relação ciência/tecnologia/sociedade, é nutrida pela dialética da denúncia daquelas intempéries e pelo anúncio da possibilidade de um mundo melhor, mais humanizado. Para tanto, é necessária a (re) construção da prática contra-valorativa aos valores do capital financeiro e do capital especulativo. Isso só é possível na medida em que nos conhecemos e reconhecemos como

[...] seres condicionados, mas não determinados. Reconhecer que a história é tempo de possibilidade e não de determinismo, que o futuro, permita-se-me reiterar, é problemático e não inexorável. (FREIRE, 1997, p. 21)

A necessária antipatia à lógica do mercado reside, professor-pesquisador, na prática docente ética e humana, porque

[...] a ideologia fatalista, imobilizante, que anima o discurso neoliberal anda solta no mundo. Com ares de pós-modernidade, insiste convencer-nos de que nada podemos contra a realidade social que, de histórica e cultural, passa a ser ou vir a ser quase natural. Frases como a realidade é assim mesmo, que podemos fazer? Ou o desemprego no mundo é uma fatalidade do fim do século expressam bem o fatalismo desta ideologia e sua indiscutível vontade imobilizadora. (FREIRE, 1997, p. 21-22)

O professor-pesquisador-reflexivo consegue (re)articular ciência/tecnologia/ sociedade e problematizá-las junto aos contextos socioculturais dos homens e das mulheres, na perspectiva de esclarecer e de demolir o mito da "sociedade da normalidade" (FOUCAULT, 2005) e das relações de poder reproduzidas no cotidiano local e global. Para isso,
[...] Creio que é preciso examinar o modo como, nos níveis mais baixos, os fenômenos, as técnicas, os procedimentos de poder atuam; mostrar como esses procedimentos, é claro, se deslocam, se estendem, se modificam, mas, sobretudo, como eles são investidos, anexados por fenômenos globais, e como poderes mais gerais ou lucros de economia podem introduzir-se no jogo dessas tecnologias, ao mesmo tempo relativamente autônomas e infinitesimais. (FOUCAULT, 2005, p. 36)

A prática docente é gravitada por microrrelações de poder, sem as quais seria impossível a reprodução do status quo hegemônico elitista. O ritual didático-pedagógico, centrado na transmissão mecânica e descontextualizada, almeja estabelecer e instituir o consenso silenciador dos valores contra-hegemônicos existentes no ambiente escolar.

O professor na sala de aula, com o seu olhar e com a sua fala, vigiando e controlando o tempo, o espaço e o raciocínio dos alunos, atribui notas (valores), classifica e os seleciona meritocraticamente. Somos vigiados e incorporados como "[...] as crianças, os escolares, os colonizados, sobre os que são fixados a um aparelho de produção e controlados durante toda a existência.[...].” (FOUCAULT, 2000, p. 28).

O trabalho docente, conivente com o poder hegemônico dos donos do mundo (que impõe o ideário da formação do trabalhador, baseado na filosofia toyotista), garante a manutenção da ordem do cenário neoliberalizante (maquiada de um discurso da prática solidária e cidadã), ou seja, oculta a essência da face deste. Neste contexto, ele é o agente do processo de dominação:

[...] dominação, não que dizer o fato maciço de uma dominação global de um sobre os outros, de um grupo sobre o outro, mas 
as múltiplas formas de dominação que podem se exercer no interior da sociedade. (FOUCAULT, 2005, p. 31-32)

A formação da prática docente contraideológica (nucleada na concepção do professor-pesquisador-reflexivo) requer, ainda, a perene leitura do mundo (com o olhar, com palavras, com o tato, com o olfato, com a audição) com amor à vida. Aquela é (re) criada com a leitura crítica dos discursos, que estão subjacentes aos contextos, escondidos nas entrelinhas dos textos. Freire (1999b, p. 11) elucida:

A leitura do mundo precede a leitura da palavra, daí que a posterior leitura desta não possa prescindir da continuidade da leitura daquela. Linguagem e realidade se prendem dinamicamente. A compreensão do texto a ser alcançada por uma leitura crítica implica a percepção das relações entre o texto e o contexto.

As vivências, (re)produzidas no contexto escolar, são atravessadas pelas ideologias que interferem nas práticas docentes, seja o da sala de aula, o do hall e o do corredor, isto é, em todos os espaços da instituição. Assim, as

[...] escolhas em relação ao saber, ao fazer e à forma de ser que se privilegia, aos caminhos trilhados pela escola pública e pela sociedade em geral são, ao mesmo tempo, efeito e instrumento de poder. Emergem de confrontos que fortalecem algumas tendências e geram outras. [...] Admitimos que a formação acadêmica é uma parte importante no processo de formação da identidade profissional, mas não é o único aspecto que determina os perfis assumidos pelo professor ao longo de sua carreira. (CARDOSO, 2003, p. 24)

É fundamental que os formadores da prática do professor-pesquisador-reflexivo estejam atentos aos saberes que circundam a vida dos seus formandos. No processo de descoberta dos saberes implícitos em seus discursos e em seus fazeres, há a possibilidade de (re) inventar as práticas (re)afirmativas da cultura do saber problematizado e, paulatinamente, (re)construir as possibilidades de ensinar e de aprender reciprocamente. Desse modo,

[...] é fundamental fazer com que os professores se apropriem dos saberes de que são portadores e os trabalhem do ponto de vista teórico e conceptual (CONTOIS; PINEAU, 1991). [Enquanto] A maneira como cada um de nós ensina está directamente dependente daquilo que somos como pessoa quando exercemos o ensino. (NÓVOA, 1992, p. 17)

Se o professor formador de professores pesquisadores-reflexivos não estiver impregnado de esperança e da utopia éticohumana da possibilidade de uma educação crítica, radical e insubmissa, jamais dará testemunho dos sonhos e dos desejos dos excluídos da terra, impedindo-os de se tornar concretude, ou seja, realidade. Sua prática será marcada e atravessada, caso não se convença de que não está imune das intempéries da globalização neoliberal, pelo discurso do impossível, do "não tem jeito".

Cuidado, professor formador, a sua prática direta ou indiretamente influenciará na (re)construção da identidade do professor-pesquisador-reflexivo. A identidade não é um atributo do determinismo biológico e cultural:

A identidade não é um dado adquirido, não é um produto. A identidade é um lugar de lutas e de conflitos, é um espaço de construção de maneiras de ser e de estar na profissão. Por isso, é mais adequado falar em processo identitário, realçando a mescla dinâmica que caracteriza a maneira como cada um se sente e se diz professor. (NÓVOA, 1992, p. 16) 
O processo de construção da prática identitária do professor-pesquisador-reflexivo traduz-se na (re)produção crítico-dialética do currículo. Dessa forma, o

[...] currículo, aqui, é uma prática, ou melhor, uma práxis, pois envolve ação e reflexão por parte do professor, que se constitui no seu principal protagonista. (PONTE, 2002a, p. 2)

A sala de aula, local onde a práxis identitária do professor emerge (conforme interesses e valores), materializa-se e corporifica-se nas produções científicas, tecnológicas e culturais presentes no ambiente da escola. O fundamento da prática identitária do educador "[...] tanto na sala de aula como na escola é a atividade investigativa, no sentido de atividade inquiridora, questionante e fundamentada.” (PONTE, 2002b, p. 2)

A formação do professor-pesquisadorcrítico-dialético, se desenvolve à proporção que se entende e se reconhece a investigação como a força motriz de um[...] processo privilegiado de construção de conhecimento. A investigação sobre a prática é, por consequência, um processo fundamental de construção do conhecimento sobre essa mesma prática e, portanto, uma atividade de grande valor para o desenvolvimento profissional dos professores que nela se envolvem. (PONTE, 2002c, p. 3).

O conhecimento unodisciplinar prevaleceu, durante muito tempo, na prática docente, assentado na racionalidade técnica. $\mathrm{O}$ cotidiano de sala de aula, nessa concepção, é obscurecido e silenciado. As linguagens presentes neste, quando silenciadas e obscurecidas, são negadas. Fleuri (2002, p. 68) enfatiza que no Brasil [...] O silêncio, o isolamento, a descrença, elementos fundamentais da cultura do medo, começaram, entretanto, a ser quebrados no final da década 1970. Emergiram os movimentos de base, assentados, sobretudo nas associações de moradores, nas comunidades eclesiais de base (CEBs) e nos novos movimentos sindicais.

A racionalidade técnica fragmenta e descontextualiza o conhecimento científico do saber popular, como se aquele não tivesse por base este. A prática do professor se intitula neutra. Sob essa ótica, o ensino é hiperespecializado e estéril, negando, assim, a possibilidade do diálogo entre as ciências. Além disso, provocou a [...] cisão entre a pesquisa e a prática educacional, reforçando hierarquização entre o discurso de quem produz e de quem consome conhecimento científico. Nessa perspectiva, vemos reproduzida a distinção entre ciência [teoria] e senso comum [prática] tão própria do pensamento moderno. (CHAVES, 2000, p. 42).

O irrisório e efêmero diálogo entre as ciências, isto é, entre as disciplinas científicas corroborou para a fragmentação, compartimentalização e hierarquização do saber. Num passado recente, a cátedra científica deleitava-se no poder outorgado pelos seus pares. Poucos a contestaram. Há um distanciamento entre as descobertas e as invenções técnico-científicas e a sociedade. Assim,[...] o desenvolvimento anterior das disciplinas científicas, tendo fragmentado e compartimentado mais e mais o campo do saber, demoliu as entidades naturais sobre as quais sempre incidiram as grandes interrogações humanas: o cosmo, a natureza, a vida e, a rigor, o ser humano. (MORIN, 2001, p. 26).

A formação da prática do professor-pesquisador-reflexivo, desse modo, não se baseia no paradigma da racionalidade técnica e neopositivista, porque se fundamenta na educação da complexidade. Morin (2001, p. 37) contraria aquele paradigma ao refletir: Trazemos, dentro de nós, o mundo físico, o mundo químico, o mundo vivo e, ao mesmo tempo, deles estamos separados por nosso 
pensamento, nossa consciência, nossa cultura. Assim, cosmologia, ciências da terra, biologia, ecologia permitem situar a dupla condição humana: natural e metanatural.

A educação da complexidade centraliza-se, sobretudo, na produção e na problematização dos conhecimentos e dos saberes articulados com a tecnologia, a ciência e sociedade, num permanente diálogo entre elas. A prática do professor-pesquisador-reflexivo toma por base o processo de que "[...] conhecer o humano não é separá-lo, mas situá-lo" (MORIN, 2001, p. 24) nos múltiplos contextos existentes, sejam culturais e sociais, sejam geopolíticos e geoeconômicos.

O paradigma da complexidade moriniano, ao contribuir para a formação da prática docente, antes de tudo, convida a (re) pensarmos a relação dialética parte-todo, problematizando as produções dos homens e das mulheres, tendo como referência, também, os seus contextos. Suas linguagens, seus pensamentos, suas culturas, as tecnologias, as suas ciências devem ser reconhecidas, sempre na relação texto-contexto-texto.

A educação, nessa perspectiva, não comunga com o pensamento aparentemente neutro, cientificista, positivista. Todo pensar é intencional, ou seja, está direcionado a um contexto, interligado a outros contextos. (Re)pensar o microcontexto de uma comunidade negra ou indígena, por exemplo, não está desligado de (re)pensar o contexto planetário. Morin (2001, p. 25) incisivamente nos alerta: “[...] para pensar localizadamente, é preciso pensar globalmente, como para pensar globalmente é preciso pensar localizadamente.”

Assim sendo, a formação da prática do professor-pesquisador-reflexivo, para o século XXI, deverá superar, especialmente, a pseudovisão da racionalidade técnica, que dividiu e divide o homem em minúsculas partes para estudá-lo cientificamente. A tecnociência conduziu a diminuição da possibilidade de conhecer e problematizar o homem na sua totalidade, ignorando as partes integrantes do todo. Morin (2000, p. 58) salienta:

[...] o século XXI deverá abandonar a visão unilateral que define o ser humano pela racionalidade (Homo sapiens), pela técnica (Homo faber), pelas atividades utilitárias (Homo economicus), pelas necessidades obrigatórias (Homo prosaicus)

A escola é um mundo. O mundo é uma escola. Os contextos externos e internos se influenciam mutuamente. Os homens e as mulheres não chegam à sala de aula desprovidos de saberes e de conhecimentos. Trazem consigo as vivências, as marcas, as falas, ou seja, imprimem ao contexto escolar o cotidiano do seu bairro, da sua rua, da sua travessa, sua ponte, seu sítio, seu igarapé, seu rio, sua vida. Isso acontece no cotidiano da escola e da comunidade, porque "[...] o ser humano não só vive de racionalidade e de técnica, ele se desgasta, se entrega, se dedica a danças, transes, mitos, magias, ritos.” (MORIN, 2000, p. 58-59).

Educar para a vida passa, então, pelo rompimento com a educação, pautada na transmissão, na centralização e na burocratização da vida escolar. Assim,

[...] educar realmente na vida e para à vida, para essa vida diferente, e para superar desigualdades sociais, a instituição educativa deve superar definitivamente os enfoques tecnológicos, funcionalistas, burocratizantes, aproximando-se, ao contrário, de seu caráter mais relacional, mais dialógico, mais cultural-contextual e comunitário. (IMBERNÓN, 2000, p. 7)

Os formadores da prática dos professores devem estar cientes das responsabilidades científicas, políticas, éticas, culturais e 
sociais, de formar um professor pesquisador, crítico e dialético capaz de estabelecer o (re) encontro das ciências e destas com os saberes populares, pois nestes estão subjacentes várias compreensões de própria ciência. Para tanto, é preciso, antes de tudo,

[...] formar um professor como um profissional prático-reflexivo que se defronta com situações de incerteza, contextualizadas e únicas, que recorre à investigação como uma forma de decidir e de intervir praticamente em tais situações. (IMBERNÓN, 1994, p. 39)

Os cursos de formação docente reflexiva e investigativa devem, ainda, possibilitar aos professores

[...] conhecimentos, habilidades e atitudes para desenvolver profissionais reflexivos ou investigadores. Nesta linha, o eixo fundamental do currículo de formação do professor é o desenvolvimento da capacidade de refletir sobre a própria prática docente, com o objetivo de aprender a interpretar, compreender e refletir sobre a realidade social e a docência. (IMBERNÓN, 1994, p. 39)

A prática do professor-pesquisadorreflexivo é o núcleo do currículo dos cursos de formação continuada de professores, que consideram o ensino, a pesquisa e a reflexão fundamentos da práxis docente. Por isso,

Quando se considera que o currículo só se materializa no ensino, momento em que os alunos e professores vivenciam experiências nas quais constroem e reconstroem conhecimentos e saberes, compreende-se a recorrente referência à prática e à formação docente nos estudos que tomam o currículo como objeto de suas atenções. (MOREIRA, 2001, p. 82)

\section{Considerações finais}

O mundo natural está interligado ao mundo social, cultural, biológico, físico, químico, matemático, (re)formando o ecossistema e (des)ordenando o cosmo. Eles estão intrinsecamente presente um no corpo do outro, ou seja, estão no corpo e na alma da terra. Qualquer prática impensada e imbecil dos homens e das mulheres provocará a presença da desordem e desarmonia, isto é, do desequilíbrio entre esses mundos.

A formação da prática do professor-pesquisador-reflexivo, aliada à mudança de mentalidade cultural xenófoba e etnocêntrica à mentalidade da pluralidade cultural, ética, cidadã, (re)encontra-se na relação da antropoética com a natureza. Adiciona-se a essa relação a utilização prudente e responsável das descobertas e invenções científicas e tecnológicas (das rudimentares, das aperfeiçoadas e sofisticadas). Precisamos, assim, converter toda nossa vontade, nosso desejo, nossa práxis antropológica e cosmológica, ou seja, nossa vida à centralidade da biosfera, considerando sempre a conexão fauna, flora, pessoas, tecnologias e as ciências.

A prática do professor não é inocente, nem desinteressada. Escolhemos, ou alguém escolhe, o paradigma da racionalidade técnica ou ainda o paradigma da epistemologia da prática, da complexidade da educação, que lhe é mais conveniente.

A prática docente da racionalidade técnico-científica desagrega as ciências da vida, do devir. A prática do professor da racionalidade prática epistemológica religa essas construções culturais.

O professor-pesquisador-reflexivo (re) constrói o permanente encontro entre os diversos saberes. Sua prática é o movimento ininterrupto que (re)cria, (re)pensa e (re)articula os conteúdos científicos e tecnológicos com 
a complexidade da vida cósmica, empírica, cultural. Sua práxis, a todo momento, baseada na relação pesquisa/ensino/reflexão/ mundo, (re)faz a corporeidade dos saberes culturais das brincadeiras, dos jogos, dos modelos, como meio de (re)produzir, deste modo, os conhecimentos matemáticos.

Pesquisando a sua prática, o professor intervém científica, tecnológica e politicamente, tanto no contexto da escola como no contexto da comunidade (FREIRE, 1997).

As experiências cotidianas nos contextos culturais só poderão contribuir para (re)pensar e (re)construir o pensamento teórico, com a presença do professor-pesquisador-reflexivo. Ressalte-se que

[...] A própria vida cotidiana passa a exigir conhecimentos desenvolvidos entre outras esferas de objetivações, o que reafirma a importância da apropriação dos conteúdos escolares para a formação do indivíduo. Da mesma forma, os conteúdos escolares tornam-se exigência para a continuada elaboração das objetivações para-si. Os conceitos escolares, além de promoverem a apropriação dos conceitos científicos, promovem também o desenvolvimento da sensibilidade artística, da postura filosófica, da análise política, de comportamentos morais etc. (BACHELARD, 1985, p. 16).

Pelas razões acima descritas, a experiência cotidiana reúne plenas possibilidades de mediar o diálogo da empiria com a ciência no sentido de instituir o (re)encontro com o mundo. Ainda conforme Bachelard (1985, p. 16), "Para interdizer radicalmente as conclusões de uma teoria, é preciso que a experiência nos exponha as razões de sua explicação.”

\section{Referências}

ALVES, N. (Org.). Formação de professores: pensar e fazer. 4. ed. São Paulo: Cortez, 1996.

APPLE, M. W. Política cultural e educação. São Paulo: Cortez, 2001.

ANDRÉ, M. Pesquisa, formação e prática docente. In: (Org.). O papel da pesquisa ma formação e na prática dos professores. Campinas, SP: Papirus, 2001.

BACHELARD, G. O novo espírito científico. 2. ed. Rio de Janeiro: Tempo Universitário, 1985.

BORTONI-RICARDO, S. M. O professor pesquisador: introdução à pesquisa qualitativa. São Paulo: Parábola, 2008.

CARDOSO, L. A. M. Formação de professores: mapeando alguns modos de ser professores ensinados por meio do discurso científico-pedagógico. In: PAIVA, E. V. de (Org.). Pesquisando a formação de professores. Rio de Janeiro: DP\&A, 2003.

CHAVES, S. N. Por uma nova epistemologia da formação docente: o que diz a literatura e o que fazem os formadores. In: SCHNETZLER, R. P.; ARAGÃO, R. M. R. (Orgs.). Ensino de ciências: fundamentos e abordagens. Campinas: R. Vieira Gráfica e Editora Ltda, 2000.

FLEURI, R. M. Multiculturalismo e interculturalismo nos processos educacionais. In: CANDAU, V. M. (Org.). Ensinar e aprender: sujeitos, saberes e pesquisa. 2. ed. Rio de Janeiro: DP\&A, 2002.

FOUCAULT, M. Vigiar e punir: história da violência nas prisões. 22. ed. Petrópolis: Vozes, 2000. 
M. Em defesa da sociedade. São

Paulo, SP: Martins Fontes, 2005.

FREIRE, P. Ação cultural para a liberdade e outros textos. 8. ed. São Paulo: Paz e Terra, 1987.

A importância do ato de ler: em três artigos que se completam. 37. ed. São Paulo: Cortez, 1999a.

Pedagogia da autonomia: saberes necessários à prática educativa. São Paulo: Paz e Terra, 1997.

Pedagogia do oprimido. 27. ed. São Paulo: Paz e Terra, 1999b.

FRIGOTTO, G. Educação e a crise do capitalismo real. 2. ed. São Paulo: Cortez, 1996.

GENTILI, P. Adeus à escola pública: a desordem neoliberal, a violência do mercado e o destino da educação das maiorias. In:

(Org.). Pedagogia da exclusão: crítica ao neoliberalismo em educação. 3. ed. Petrópolis: Vozes, 1995.

IMBERNÓN, F. La formación del profesorado. Espanha: Paidós, 1994.

Formação docente profissional: formar-se para a mudança e a incerteza. São Paulo: Cortez, 2000.

LUCENA, I. C. R. de. Matemática escolar e saber popular: buscando convergências. In: CUNHA, E. Ribeiro; SÁ, P. F. (Orgs.). Ensino e formação docente: propostas, reflexões e práticas. Belém: [s.n.], 2002.

LÜDKE, M. (Coord.). O professor e a pesquisa. São Paulo: Papirus, 2001a.

A complexa relação entre o professor e a pesquisa. In: ANDRÉ, M. (Org.). O papel da pesquisa na formação e na prática dos professores. Campinas: Papirus, 2001b.
MOREIRA, A. F. B. Multiculturalismo, currículo e formação de professores. In: (Org.). Currículo: políticas e práticas. 4. ed. Campinas: Papirus, 2001.

MORIN, E. A cabeça bem-feita: repensar a reforma, reformar o pensamento. 3. ed. Rio de Janeiro: Bertrand Brasil, 2001.

Os sete saberes necessários à educação do futuro. 2. ed. São Paulo: Cortez, 2000.

NIETZSCHE, F. Para além do bem e do mal: prelúdio a uma filosofia do futuro. São Paulo: Martin Claret, 2002.

NÓVOA, A. Os professores e as histórias da sua vida. In: (Org.). Vidas de professores. Porto: Porto Editora, 1992.

Diz-me como ensinas, dir-teei quem és e vice-versa. In: FAZENDA, I. (Org.). A pesquisa em educação e as transformações do conhecimento. 4. ed. Campinas: Papirus, 2002.

PAIVA, E. V. de (Org.). Pesquisando a formação de professores. Rio de Janeiro: DP\&A, 2003.

PERRENOUD, P. Saber refletir sobre a própria prática: objetivo central da formação dos professores. In: prática reflexiva no ofício de professor: profissionalização e razão pedagógica. Porto Alegre: Artmed, 2002.

PONTE, J. P. de. Investigar a prática. Departamento de Educação e Centro de Investigação em Educação. Faculdade de Ciências da Universidade de Lisboa. Lisboa: [s.n.], 2002a. Mimeografado.

Por uma formação inicial de professores de qualidade. Lisboa: Documento de trabalho da Comissão ad hoc do CRUP para a formação de professores, 2002b. 
et al. O início da carreira profissional de jovens professores de matemática e ciências. Departamento de Educação e Centro de Investigação em Educação. Faculdade de Ciências da Universidade de Lisboa. Lisboa: [s.n.], 2002c. Mimeografado.

SCHÖN, D. Educando o profissional reflexivo: um novo design para o ensino e a aprendizagem. Porto Alegre: Artes Médicas, 2000.

La formación de profesionales reflexivos: un nuevo diseño de la enseñanza y el aprendizaje em las profesiones. San Francisco - Londres: Paidós Ibérica, 1992.

SUÁREZ, D. O princípio educativo da nova direita: neoliberalismo, ética e escola pública. In: GENTILI, P. (Org.). Pedagogia da exclusão: crítica ao neoliberalismo em educação. 3. ed. Petrópolis: Vozes, 1995.

TEIXEIRA, M. L. C. A formação do professor de matemática e a pesquisa em sala de aula. Educação Matemática em Revista, ano 9, n. 12, jun. 2002.

ZEICHNER, K. A formação reflexiva de professores: ideias e práticas. Lisboa: EDUCA, 1993.

Enviado em: 24/05/2011

Aceito em: 20/12/2011 